\title{
Rancang Bangun Game Edukasi Pembelajaran Untuk Anak Usia Dini ( 2 - 6 Tahun ) Berbasis Android
}

\author{
Teguh Hidayat Iskandar Alam ${ }^{1}$, Rendra Soekarta ${ }^{2}$, Mulyaddin ${ }^{3}$ \\ 1,2,3 Prodi Teknik Informatika, Universitas Muhammadiyah, Sorong \\ e-mail: ${ }^{1}$ teguhhidhayat@gmail.com,${ }^{2}$ rendrasoekarta@gmail.com, ${ }^{3}$ mulyaddin.um@gmail.com
}

\begin{abstract}
Abstrak
Media pembelajaran yang biasa digunakan oleh orangtua untuk anaknya adalah media cetak atau kertas yang berupa gambar, grafik, maupun buku. Seringkali banyak anak merasa cepat bosan dan tidak tertarik dengan materi pembelajaran yang diajarkan jika diajarkan dengan metode belajar yang biasa dengan menggunakan media cetak. Sehingga anak terkadang kesulitan mengenal huruf, angka, hewan, buah dan profesi yang ada dibuku. Tujuan dari penelitian ini adalah menghasilkan metode pembelajaran yang baru berupa game edukasi yang dapat digunakan oleh anak dalam mempelajari dan mengenal huruf, angka, hewan, buah, dan profesi yang ada disekitar dengan berbasis smartphone android menggunakan tools android studio.
\end{abstract}

Kata kunci : Metode Pembelajaran, Game Edukasi, Smartphone, Android, Android Studio.

\section{PENDAHULUAN}

$\mathrm{P}$ endidikan Anak Usia Dini merupakan suatu upaya pembinaan yang ditujukan kepada anak sejak lahir sampai dengan usia enam tahun. Upaya pembinaan dilakukan

melalui pemberian rangsangan Pendidikan untuk membantu dalam hal pertumbuhan dan perkembangan jasmani dan rohani agar anak memiliki kesiapan dalam memasuki jenjang Pendidikan lebih lanjut (UU No. 20 Tahun 2003)[1].

Media pembelajaran merupakan alat bantu proses belajar mengajar. Media pembelajaran yang biasa digunakan oleh orangtua untuk anaknya adalah media cetak atau kertas yang berupa gambar, grafik, maupun buku. Sedangkan teknologi terus mengalami kemajuan terutama media elektronik yang dapat mengolah dan menampilkan gambar, suara, animasi, maupun video[2], [3].

Seringkali banyak anak merasa cepat bosan dan tidak tertarik dengan materi pembelajaran yang diajarkan jika diajarkan dengan metode belajar yang biasa dengan menggunakan media cetak. Sehingga anak terkadang kesulitan mengenal huruf, angka, hewan, buah dan profesi yang ada dibuku. Diharapkan dari materi ini dapat diaplikasikan dalam kehidupan sehari-hari anak, sehingga anak dapat mengenali huruf, angka, hewan, buah, dan profesi yang ada disekitar mereka. Sehingga dibutuhkan aplikasi dalam hal ini yaitu game yang dapat membantu dalam menyampaikan materi pembelajaran kepada anak menggunakan metode yang berbeda dari yang biasa digunakan[4], [5].

“Game Edukasi Pembelajaran Untuk Anak Usia Dini Berbasis Android", dibuat dengan menggunakan perangkat lunak Android Studio yang diharapkan dapat digunakan sebagai sarana alternatif dalam mempelajari materi pembelajaran. Oleh karena itu game ini diharapkan mampu mengembangkan kemampuan anak terutama berinteraksi, mengingat, dan mengenal mengenai huruf, angka, hewan, buah, dan profesi yang ada disekitar mereka. 


\section{METODE PENELITIAN}

\subsection{Pola Pendidikan Pada Anak Usia Dini}

Pola atau model pembelajaran adalah suatu desain atau rancangan yang menggambarkan proses rincian dan penciptaan situasi lingkungan yang memungkinkan anak berinteraksi dalam pembelajaran, sehingga terjadi perubahan atau perkembangan pada diri anak[6].

Penyusunan pola atau model pembelajaran untuk anak usia dini didasarkan pada silabus yang dikembangkan menjadi perencanaan semester, satuan kegiatan mingguan (SKM), dan satuan kegiatan harian (SKH). Dengan demikian, mdel pembelajaran merupakan gambaran konkret yang dilakukan pendidik dan peserta didik sesuai dengan kegiatan harian[6].

\subsection{Media Pembelajaran}

Media Pembelajaran, menurut Heinich yang dikutip oleh Azhar Arsyad adalah perantara yang membawa pesan atau informasi bertujuan intruksional atau mengandung maksud-maksud pengajaran antara sumber dan penerima[7], [8].

\subsection{Game Edukasi Anak Usia Dini}

Game sering kali dituduh memberikan pengaruh negative terhadap anak. Faktanya, Gamsse mempunyai fungsi dan manfaat positif bagi anak, di antaranya, anak mengenal teknologi komputer, pelajaran untuk mengikuti pengarahan dan aturan, latihan memecahkan masalah dan logika, melatih saraf motoric dan keterampilan spasial, menjalin komunikasi anak - orangtua saat bermain Bersama, serta memberikan hiburan[9], [10].

Edukasi sebenarnya tidak jauh berbeda dari belajar hanya istilah ini sering dimaknai berbeda dari learning yang bermakna belajar. Dan istilah ini seringkali digunakan dalam pendekatan Pendidikan yang tentu maknanya lebih dari sekedar belajar[9], [10].

Secara umum anak usia dini merupakan anak yang berada pada usia 2-6 tahun. Usia dini merupakan usia yang sangat penting bagi perkembangan anak sehingga disebut Golden Age. Anak usia dini sedang dalam tahap pertumbuhan dan perkembangan yang paling pesat, baik fisik maupun mental. Anak usia dini belajar dengan caranya sendiri, bila ditinjau dari hakikatnya anak usia dini, maka anak memiliki dua aspek perkembangan yaitu biologis dan psikologis[9], [10].

\subsection{Android}

Android merupakan system operasi open source bagi perangkat mobile yang berbasis pada system operasi Linux. Sependapat dengan Nazaruddin Android merupakan system operasi untuk telepon seluler yang berbasis Linux[7].

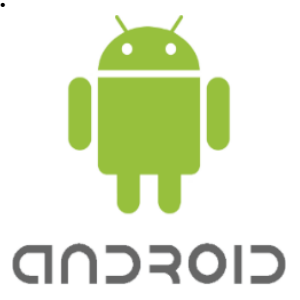

Gambar 1 Android

Pada juli 2005 Android telah diakuisisi oleh Google dan pada 5 November 2007 barulah secara resmi Android di rilis oleh Google. Dalam pengembagan aplikasi Android menyediakan Android SDK yang menyediakan tools dan API (application programming interface). API adalah sekumpulan perintah, fungsi dan protokol yang digunakan oleh pengembang (programmer) untuk pengembangan aplikasi dengan platform Android[7].

Sistem Android sebagai sistem operasi mobile yang terbuka memiliki banyak versi dalam perkembangannya. Beberapa versi pada Android ialah Android 1.5 (Cupcake), Android 
1.6 (Donut), Android 2.0 - 2.1 (Eclaire), Android 2.2 - 2.2.3 (Froyo), Android $2.3-2.3 .7$ (Gingerbread), Android 3.0 - 3.2.6 (Honeycomb), Android 4.0 - 4.0.4 (Ice Cream Sandwich), Android 4.1 - 4.3 (Jelly bean), Android 4.4+ (Kitkat), Android 5.0+ (Lolipop), Android 6.0+ (Marsmallow), Android 7.0+ (Nougat), Android 8.0+ (Oreo), dan yang terbaru adalah Android 9.0+ (Pie)[7].

\subsection{Android Studio}

Pembuatan game edukasi ini menggunakan software Android studio. Android studio merupakan sebuah Integrated Development Environmet atau IDE untuk Android Development yang dikenalkan pihak google pada acara Google I/O ditahun 2013.

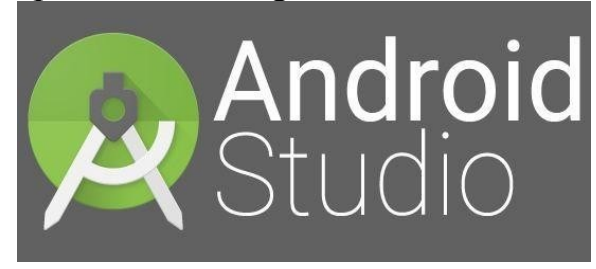

Gambar 2 Android Studio

Android studio merupakan suatu pengembang dari Eclipse IDE, dab dibuat berdasarkan IDE Java popular, yaitu IntelliJ IDEA. Android studio merupakan IDE resmi untuk pengembangan aplikasi android. Salah satu tugas utama dari android sebagai IDE adalah menyediakan interface dalam membuat aplikasi serta melakukan pengelolaan manajemen file yang bias dibilang kompleks. Bahasa programming yang digunakan adalah Java.

\section{HASIL DAN PEMBAHASAN}

\subsection{Desain UML (Unified Modeling Language)}

Desain UML digunakan untuk menyusun dan menggambarkan system pada game yang akan dibuat.

1. Usecase Sistem

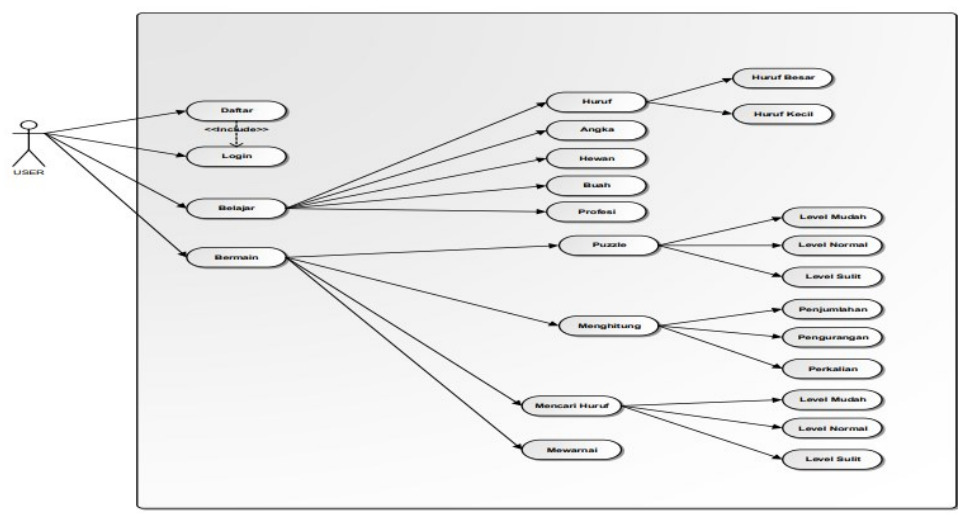

Gambar 1. Usecase Sistem

Pada gambar diatas, diagram usecase game edukasi memiliki 1 aktor yang terlibat dalam system. Actor tersebut adalah User atau Pengguna.

a. User

User merupakan actor yang terlibat dalam system dan dapat menggunakan atau menjalankan game edukasi tersebut. 
2. Activity Diagram

Activity diagram dari game edukasi ini adalah sebagai berikut:

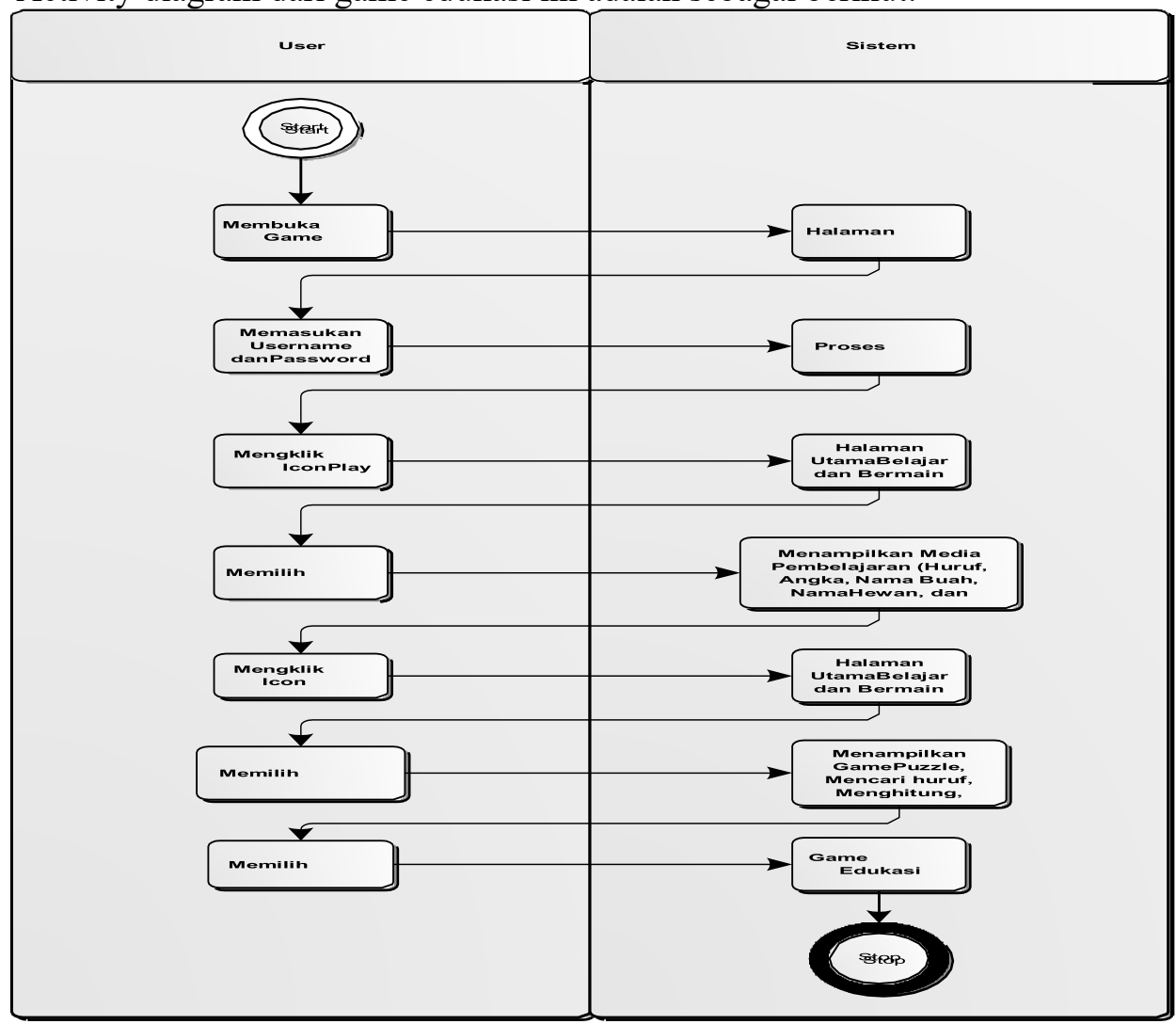

Gambar 4 Activity Diagram

Diagram aktivitas pada desain UML bertujuan untuk menggambarkan aliran kejadian yang ada pada usecase.

\subsection{Implementasi interface}

\section{Tampilan Halaman Login}

Merupakan Tampilan verifikasi dari orang tua agar dapat dijalankan atau digunakan oleh anak saat ingin belajar.

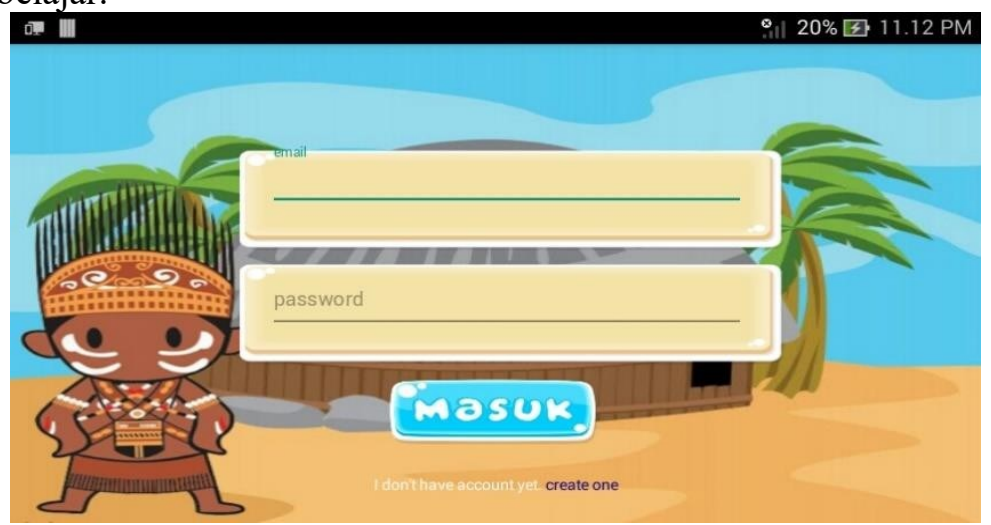

Gambar 5 Tampilan Interface Halaman Login

2. Tampilan Halaman Daftar

Merupakan Tampilan untuk membuat akun agar bisa masuk dalam game edukasi ini. 


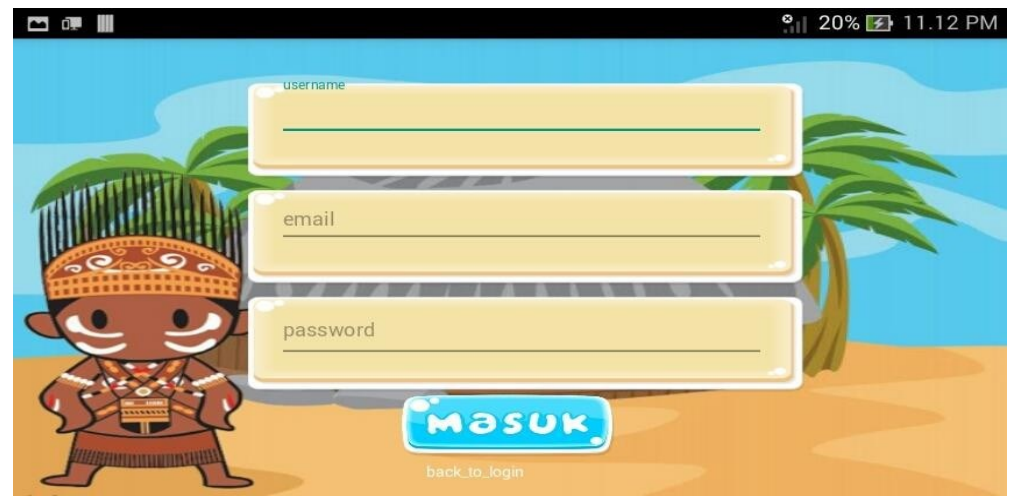

Gambar 6 Tampilan Interface Halaman daftar

3. Tampilan Utama

Merupakan tampilan awal dari project game edukasi ini, Tombol play untuk mengakses ke tampilan berikutnya.

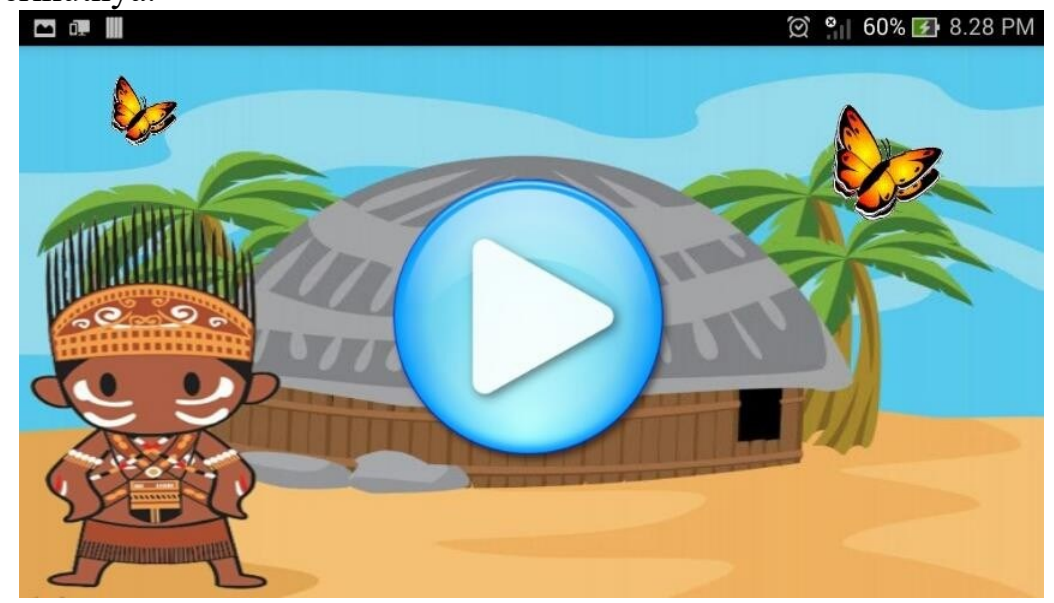

Gambar 7 Tampilan Interface Halaman Utama

4. Tampilan Menu Utama

Merupakan Tampilan Menu Utama Terdapat 2 tombol klik Belajar dan Bermain.

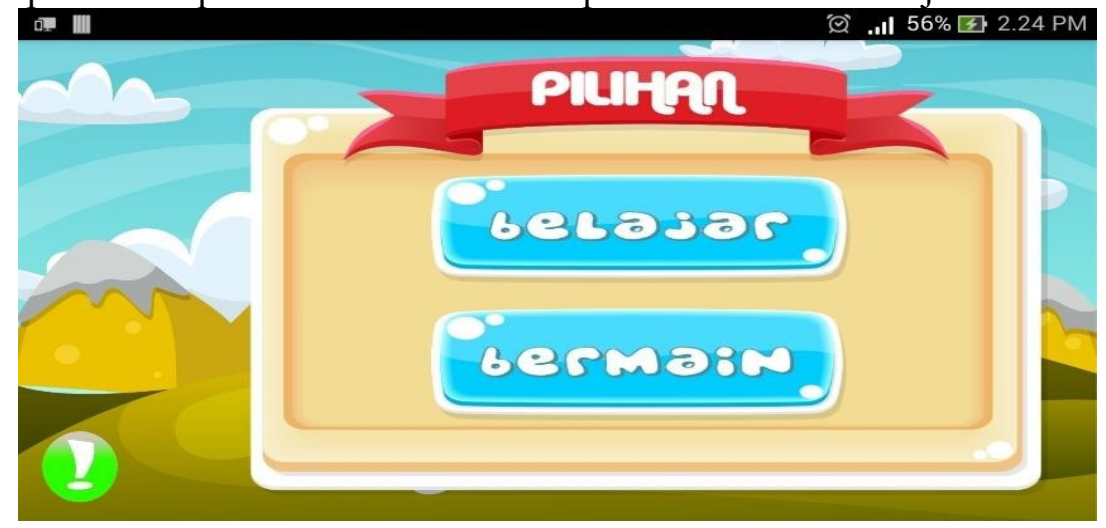

Gambar 8 Tampilan Interface Menu Utama

5. Tampilan Menu Pilihan Belajar

Merupakan tampilan dari menu pilihan Belajar terdapat beberapa kategori yaitu Kosakata, Angka, Nama Buah, Nama Hewan, dan Profesi. 


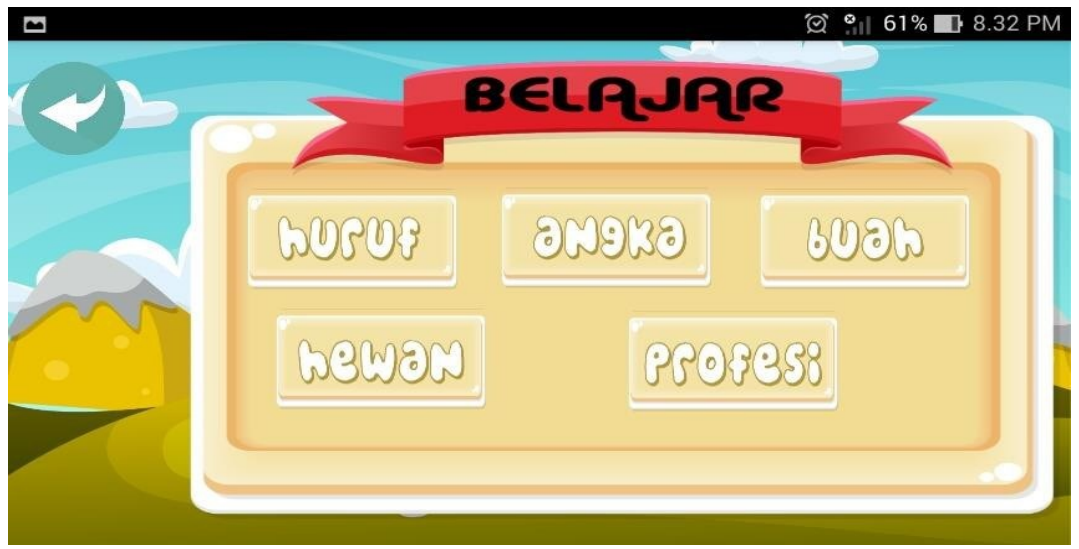

Gambar 9 Tampilan Interface Menu Pilihan Belajar

6. Tampilan Pada Game Pilihan Huruf

Merupakan Tampilan dari Menu pilihan Belajar Huruf terdapat Huruf-huruf Abjad yang dapat diklik dan menampilkan suara penyebutan dari huruf abjad tersebut.

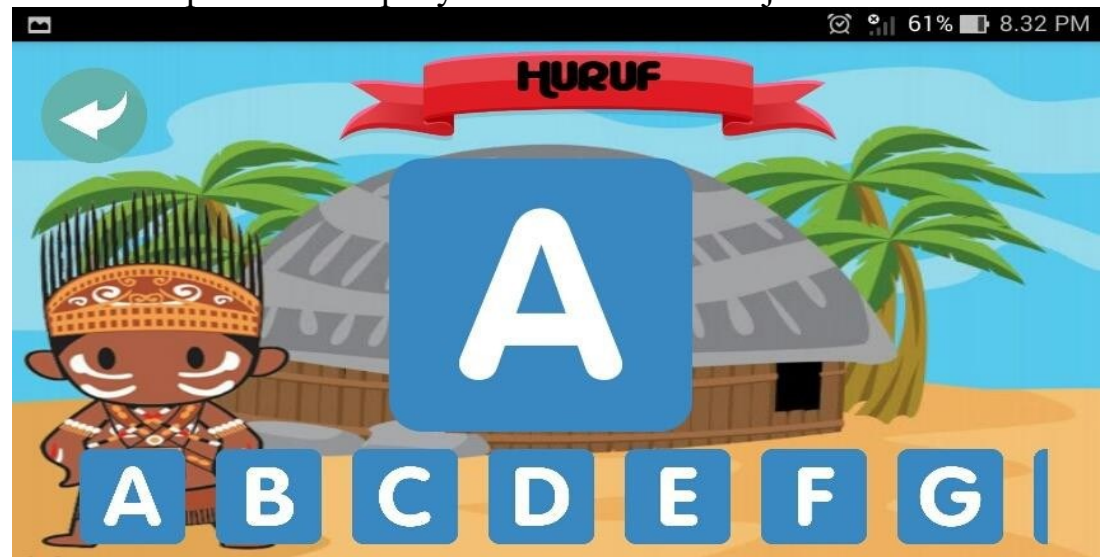

Gambar 10 Tampilan Interface Game Pilihan Huruf

7. Tampilan Pada Game Pilihan Angka

Merupakan Tampilan dari Menu pilihan Belajar Angka terdapat 20 angka wajib yang dapat diklik dan menampilkan suara penyebutan dari angka-angka tersebut.

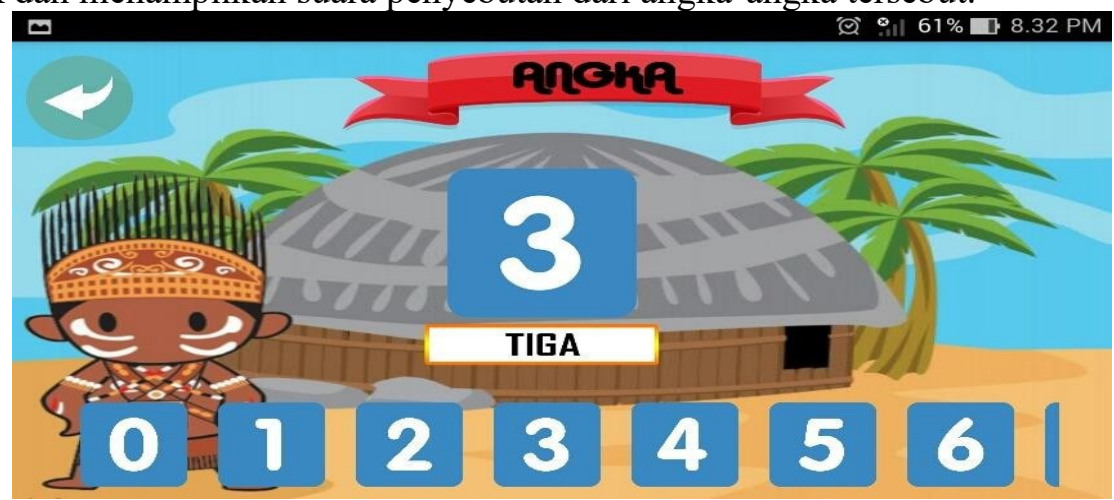

Gambar 11 Tampilan Interface Game Pilihan Angka

8. Tampilan Pada Game Pilihan Nama-Nama Buah

Merupakan Tampilan dari Menu pilihan Belajar Nama Buah terdapat Gambar buahbuahan yang dapat diklik dan menampilkan suara penyebutan dari gambar buah tersebut. 


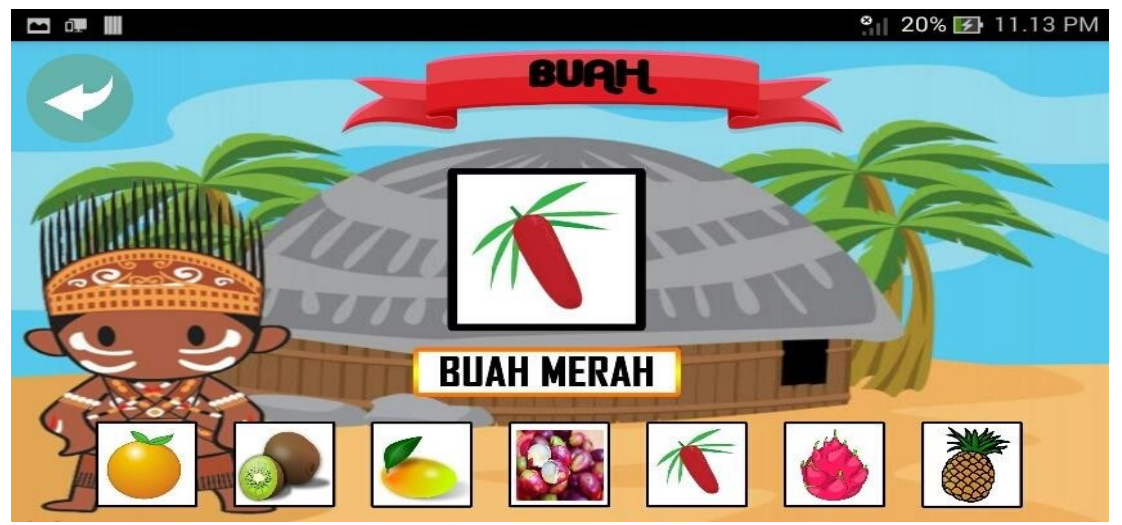

Gambar 12 Tampilan Interface Game Pilihan Nama Buah

9. Tampilan Pada Game Pilihan Nama-Nama Hewan

Merupakan Tampilan dari Menu pilihan Belajar Nama Hewan terdapat Gambar Hewan yang dapat diklik dan menampilkan suara penyebutan dari gambar hewan tersebut.

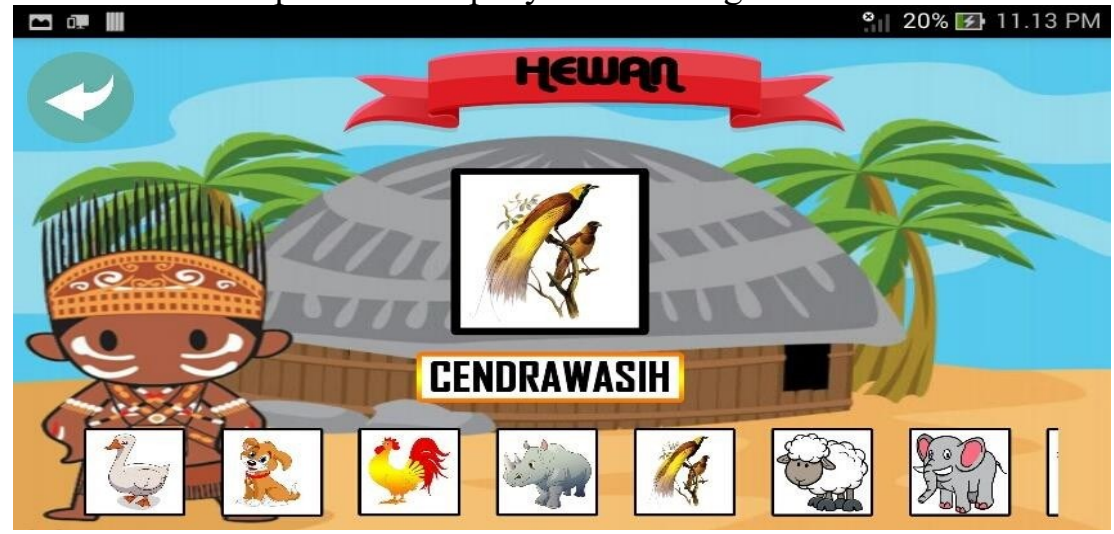

Gambar 13 Tampilan Interface Game Pilihan Nama Hewan

10. Tampilan Pada Game Pilihan Profesi

Merupakan Tampilan dari Menu pilihan Belajar Profesi terdapat Gambar Profesi yang dapat diklik dan menampilkan suara penyebutan dari gambar profesi tersebut.

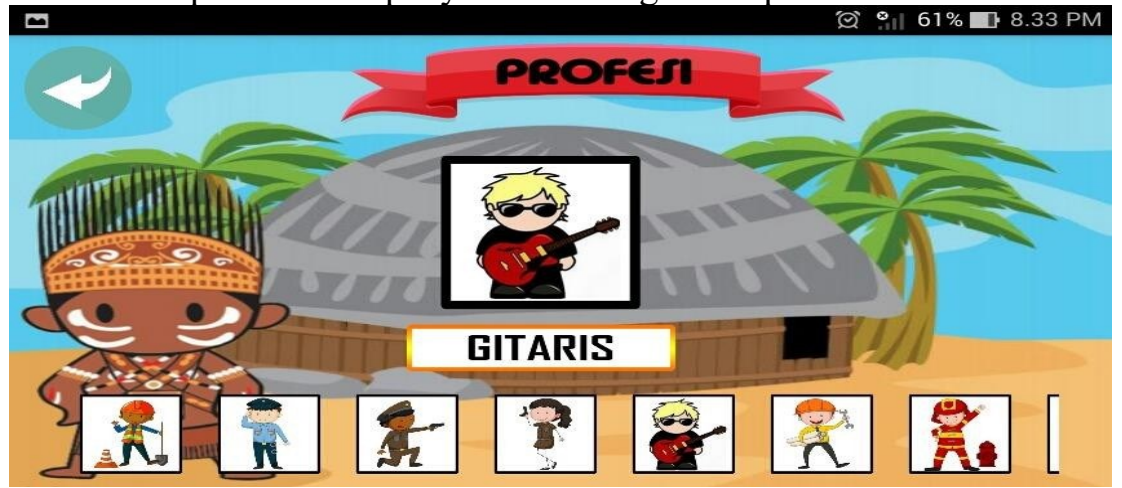

Gambar 14 Tampilan Interface Game Pilihan Profesi

11. Tampilan Pada Menu Pilihan Bermain

Ada terdapat pilihan dalam Menu Bermain 


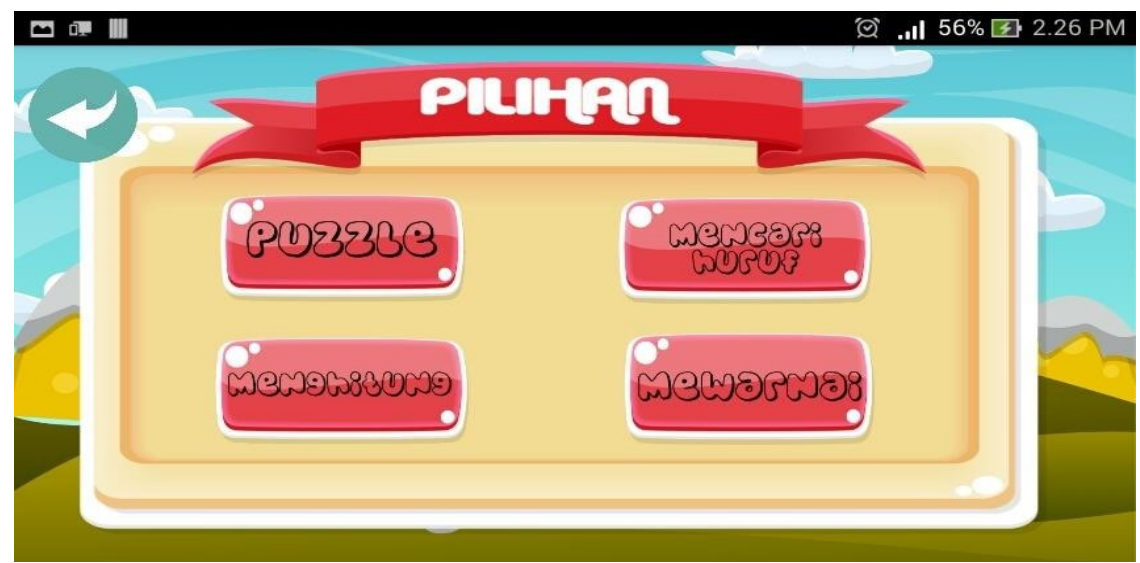

12. Game Puzzle

Gambar 15 Tampilan Menu Pilihan Bermain

Menu Pilihan Bermain dapat memainkan game puzzle bergambar didalamnya terdapat 3 level yaitu mudah, normal dan sulit.

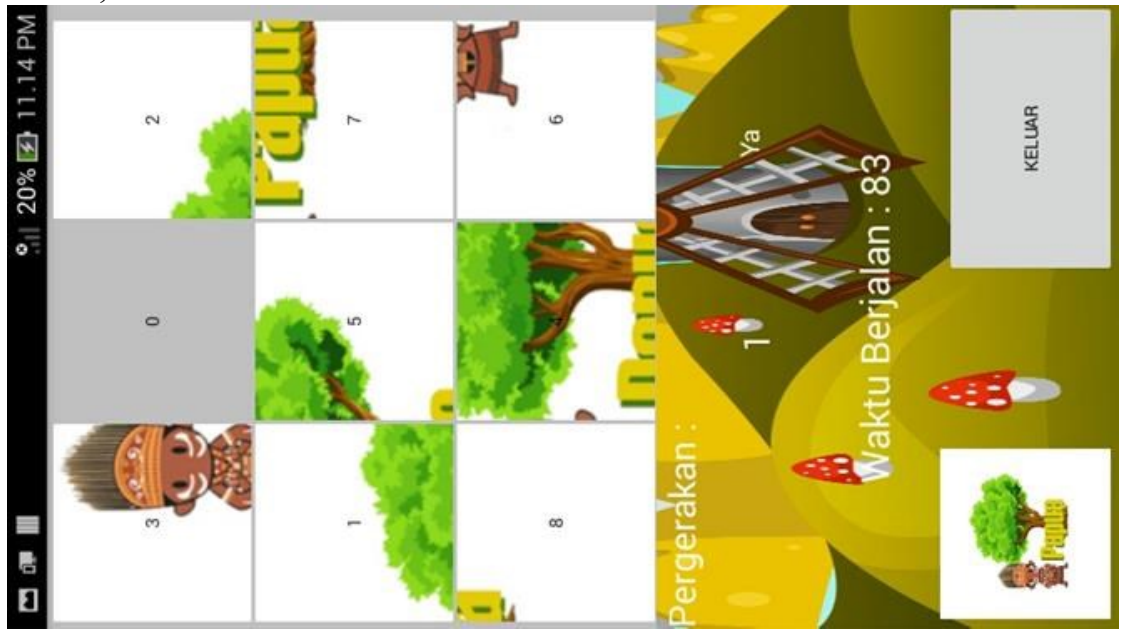

Gambar 16 Tampilan Interface Game Puzzle

13. Game Menghitung Angka

Menu pilihan bermain dapat memainkan game menghitung angka didalamnya terdapat penjumlahan, pengurangan, dan perkalian.

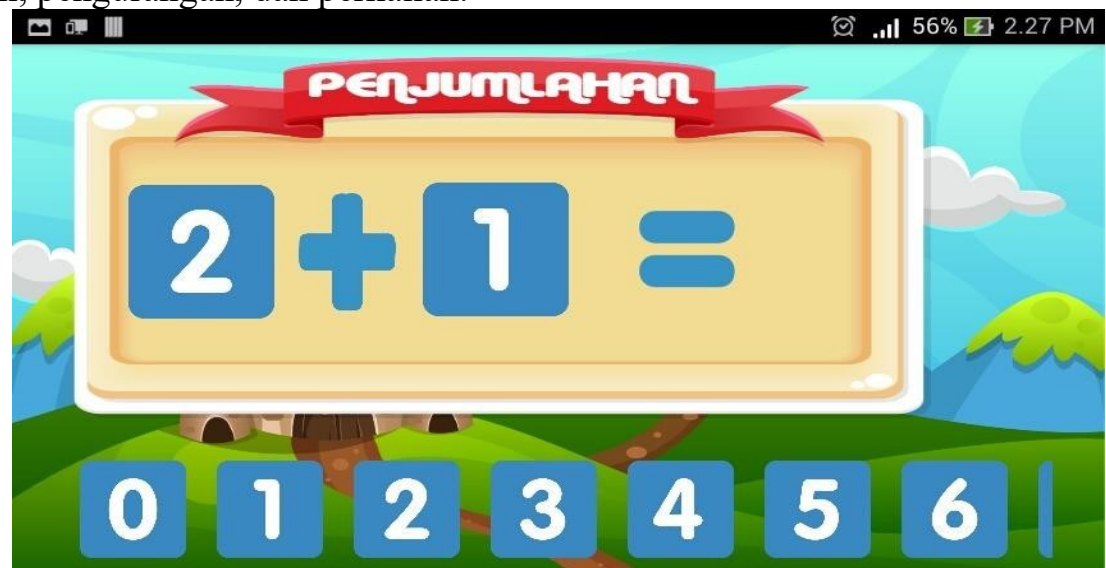

Gambar 17 Tampilan Interface Game Menghitung Angka 
14. Game Mencari Huruf

Menu pilihan bermain dapat memainkan game mencari huruf didalamnya terdapat 3 level yaitu mudah, normal, dan sulit.

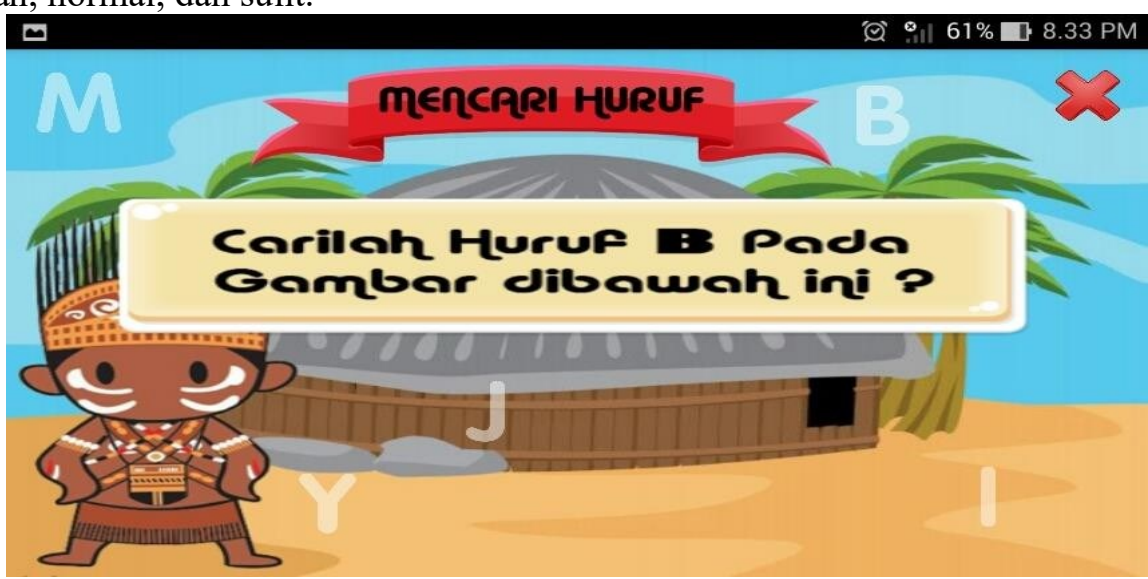

Gambar 18 Tampilan Interface Game Mencari huruf

15. Game Mewarnai Gambar

Menu pilihan bermain dapat memainkan game mewarnai gambar

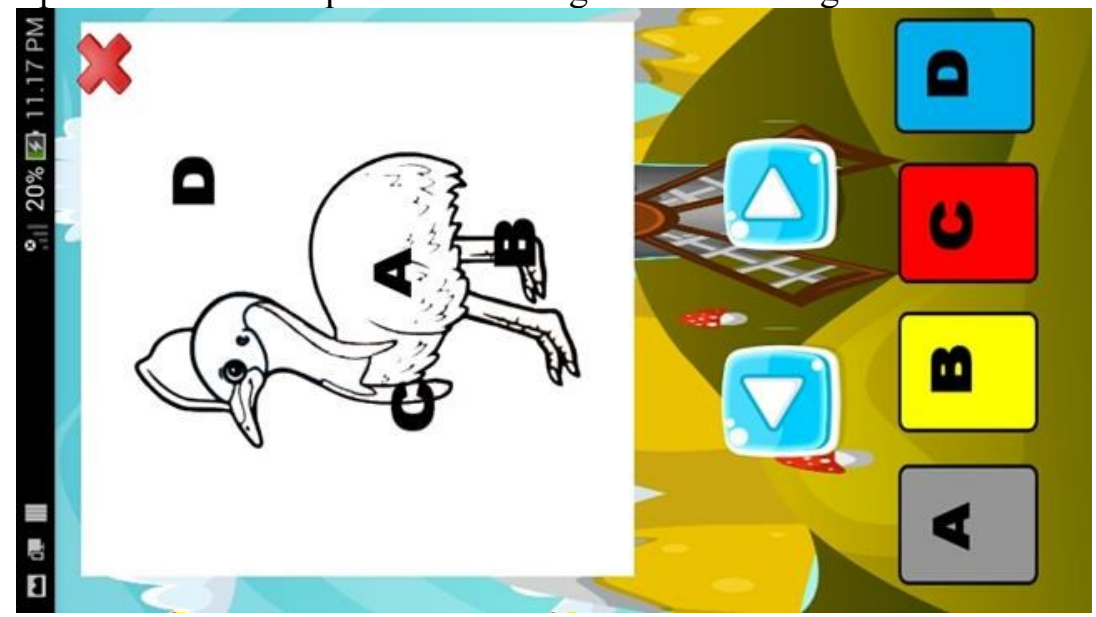

Gambar 19 Tampilan Interface Game Mewarnai Gambar

16. Tampilan About

Merupakan tampilan Profile dari penulis

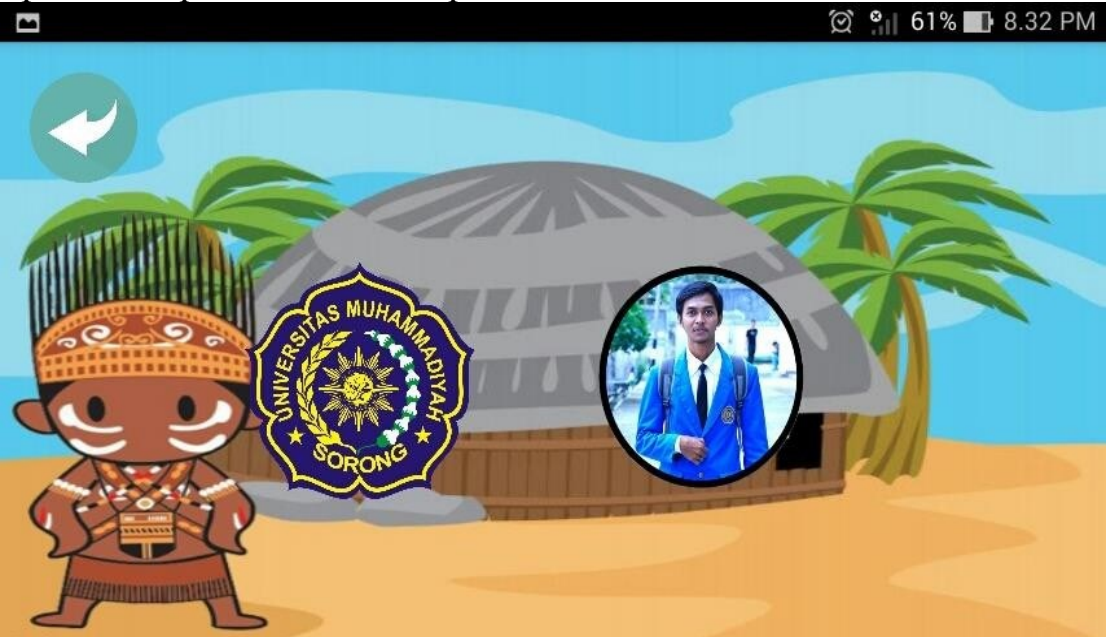

Gambar 20 Tampilan Interface About 


\section{KESIMPULAN}

Berdasarkan hasil penelitian yang telah dilakukan dapat disimpulkan bebrapa hal sebagai berikut:

1. Berhasil menghasilkan metode pembelajaran yang baru yang berupa game edukasi pembelajaran yang dapat membatu mempelajari materi pembelajaran anak.

2. Berhasil merancang dan membuat game pembelajaran anak untuk mempelajari danmengenal huruf, angka, hewan, buah dan profesi yang ada disekitar mereka.

3. Berhasil menghasilkan media pembelajaran berupa game pada smartphone yang berbasis android

\section{SARAN}

Penelitian yang dilakukan masih terdapat kekurangan dan masih dapat dikaji lebih lanjut. Oleh sebab itu penulis memberikan saran-saran terkait pengembangan game edukasi ini :

1. Game edukasi pembelajaran ini masih perlu dikembangkan lagi sebab masih banyakterdapat kekurangan pada media pembelajarannya.

2. Diharapkan agar kedepan dapat menambahkan game-game edukasi yang lebih menarikdan mampu mengasah otak pada anak usia dini.

3. Penyempurnaan tampilan user interface pada game edukasi pembelajaran ini agar lebihbaik dan menarik.

\section{UCAPAN TERIMA KASIH}

Puji syukur penulis panjatkan ke hadirat Tuhan Yang Maha Esa. Karena atas berkat rahmat karunianya penulis dapat menyelesaikan penelitian ini. Dan tidak lupa penulis mengucapkan terima kasih kepada semua pihak yang telah membantu sehingga penelitian ini dapat diselesaikan.

\section{DAFTAR PUSTAKA}

[1] N. D. Kurniasari, "Pola Pembelajaran dan Pengasuhan Pendidikan Anak Usia Dini di PAUD Madura," J. Komun., vol. 10, no. 1, p. 113, 2016, doi: 10.21107/ilkom.v10i1.1844.

[2] I. N. Sembiring, P. A. Telnoni, and T. D. Tambunan, "Aplikasi Game Edukasi Pengenalan Dan Pengelompokan Tumbuhan Untuk Mata Pelajaran Ipa Kelas 4 Sd Ar-Rafi the Application of Educational Game for the Introduction and the Grouping of Plants in Natural Science Subject for the 4 Th Graders of Sd Ar-Rafi Using," vol. 2, no. 3, pp. 11031112, 2016.

[3] F. Rahim, Game Edukasi Pengenalan Alat Musik Tradisional di Indonesia Berbasis Android. 2016.

[4] R. Carolina, "Pembangunan Aplikasi Game Edukasi Bermain dan Belajar Pada Anak Usia Dini Berbasis Android," Artik. Skripsi Univ. Nusant. PGRI Kediri, no. 27 Juli 2016, p. 9, 2016, [Online]. Available: http://docplayer.info/40410290-Pembangunan-aplikasi-gameedukasi- bermain-dan-belajar-pada-anak-usia-dini-berbasis-android.html.

[5] Soekarta, R., Amri, I., \& Hidayatulah, M. L. (2019). Perancangan Aplikasi Penagihan Pelanggan Tv Kabel Berbasis Android. Insect (Informatics and Security): Jurnal Teknik Informatika, 5(1), 11-20.

[6] M. Rais and M. Riska, "Pembelajaran Interaktif Edu-Game Pengenalan Profesi Berbasis 
Android Pada Siswa Paud," J. Psikol. Pendidik. dan Konseling J. Kaji. Psikol. Pendidik. dan Bimbing. Konseling, vol. 4, no. 1, p. 38, 2018, doi: 10.26858/jpkk.v4i1.3645.

[7] P. Jateng, "Paud Jateng web site," PAUD Jateng, 2015. https://www.paud.id/4-modelpembelajaran-paud-pembelajaran-inovatif/.

[8] T. Kusumaningrum, "PENGEMBANGAN GAME EDUKASI BERBASIS ANDROID UNTUK BELAJAR KOSAKATA BAHASA PRANCIS," 2016.

[9] Taofik Muhammad and Nurfitriani Meiliana, "Rancang Bangun Media PembelajaraTaofik Muhammad, \& Nurfitriani Meiliana. (2019). Rancang Bangun Media Pembelajaran Bahasa Inggris Berbasis Android Dengan Menggunakan Teknologi Augmented Reality Dan Location Based Service. INFOTECH Journal, 5(1), 1-7. http," INFOTECH J., vol. 5, no. $1, \quad$ pp. $1-7, \quad 2019$, [Online]. Available: https://www.jurnal.unma.ac.id/index.php/infotech/article/view/1125.

[10] D. W. P. A. P. N. Erri Wahyu Puspitarini, "Game Edukasi Berbasis Android Sebagai Media Pembelajaran Untuk Anak Usia Dini," J I M P - J. Inform. Merdeka Pasuruan, vol. 1, no. 1, pp. 46-58, 2016, doi: 10.37438/jimp.v1i1.7.

[11] D. L. Fithri and D. A. Setiawan, "Analisa Dan Perancangan Game Edukasi Sebagai Motivasi Belajar Untuk Anak Usia Dini," Simetris J. Tek. Mesin, Elektro dan Ilmu Komput., vol. 8, no. 1, pp. 225-230, 2017, doi: 10.24176/simet.v8i1.959. 